\title{
Relation of Biochemical Mutations to Actinomycin Synthesis in Streptomyces antibioticus
}

\author{
By M. POLSINELLI, A. ALBERTINI, G. CASSANI AND O. CIFERRI \\ Department of Genetics, University of Pavia, Italy
}

(Received 12 November 1964)

\begin{abstract}
SUMMARY
Biochemical mutants of Streptomyces antibioticus were isolated and tested for their capacity to produce actinomycin. The yield of actinomycin produced in minimal medium plus the required amino acid, by strains requiring an amino acid not present in the molecule of actinomycin, was not significantly different from that obtained from the wild-type strain. On the other hand, all the strains which required an amino acid, which was also a precursor of the antibiotic, showed on minimal medium a drastic decrease in the production of actinomycin. The results have been interpreted by assuming a different utilization by the cell of exogenous and endogenous amino acid pools for antibiotic and protein synthesis.
\end{abstract}

\section{INTRODUCTION}

Biochemical mutations can determine an alteration of antibiotic yield when introduced into strains of fungi or Streptomyces which produce antibiotics. Bonner (1947) isolated fifty-five mutants of Penicillium notatum which were unable to synthesize penicillin or which produced less than 5-10 units/ml. Sermonti (1957, 1959) and MacDonald, Hutchinson \& Gillett (1963) found that a large proportion of auxotrophic mutants of $\boldsymbol{P}$. chrysogenum showed a decrease of penicillin production. Similar results were reported by Alikhanian, Mindlin, Goldat \& Vladimizov (1959) for the production of oxytetracycline by auxotrophic strains of Streptomyces rimosus; they also showed that antibiotic production by some auxotrophs was increased when the specific growth factor was added in excess of the amount required for normal growth. Mach, Reich \& Tatum (1963), in a study of the biosynthesis of the polypeptide tyrocidine by Bacillus brevis, obtained several strains which were incapable of producing the antibiotic, but they did not succeed in isolating strains which were auxotrophic for amino acids present in the polypeptide. The present paper describes the effect of auxotrophy on the production of actinomycin by biochemical mutants of $S$. antibioticus. It will be shown that the nutritional dependence on the presence of an amino acid component of the polypeptide antibiotic had a more drastic effect on actinomycin yield than a nutritional dependence for other amino acids not components of the antibiotic. A possible interpretation of the results is given on the basis of a different utilization by the organisms of the exogenous and endogenous amino acid pools for protein and antibiotic synthesis. 


\section{METHODS}

Culture media. Bennett's agar (Waksman, 1961) was used for the maintenance of strains and for plating ultraviolet-irradiated spores. Medium no. 40 of Magni \& von Borstel (1962), a minimal medium adjusted to $\mathrm{pH} 7$, was used in replica plating for the isolation of biochemical mutants. The complete medium V6, used for vegetative growth, had the following composition (g./l.): yeast extract (A. Costantino, Favria, Turin, Italy), 5; beef extract (as above), 5; peptone (as above), 5 ; casein hydrolysate (as above), 3 ; glucose, $20 ; \mathrm{NaCl}, 1.5$; distilled water to $1000 \mathrm{ml}$; adjusted to $\mathrm{pH} 6 \cdot 6$; sterilized at $115^{\circ}$ for $30 \mathrm{~min}$. The complete medium V 6 and the minimal medium of Goss \& Katz (1960), in which galactose was replaced by glucose, were used for the fermentations.

Table 1. Biochemical mutants of Streptomyces antibioticus

\begin{tabular}{|c|c|c|}
\hline Code & Genotype* & Derivation \\
\hline AB 2 & $(i s o l+v a l)^{-}$ & \\
\hline AB 8 & $(i s o l+v a l)^{-}$ & \\
\hline AB 107 & $(i s o l+v a l)^{-}$ & \\
\hline AB 111 & met $^{-}$thr- & \\
\hline AB 1 & cys- & \\
\hline $\mathbf{A B} 3$ & $\arg ^{-} u^{-}$ & \\
\hline $\mathbf{A B} 9$ & $\arg ^{-} u r^{-}$ & \\
\hline $\mathrm{AB} 115$ & $\arg ^{-} u^{-}$ & \\
\hline AB 114 & $\arg ^{-}$ & \\
\hline AB 4 & his $^{-}$ & \\
\hline AB 101 & his $^{-}$ & 1692 by u.v. 1rradation \\
\hline AB 102 & his $^{-}$ & \\
\hline AB 103 & his $^{-}$ & \\
\hline AB 113 & $a d^{-}$ & \\
\hline AB 6 & phe- & \\
\hline AB 106 & leu- & \\
\hline$A B 7$ & leu- & \\
\hline$A B 10$ & leu- & \\
\hline$A B 110$ & $m^{-} t^{-}$ & \\
\hline AB 109 & $t^{\prime-}$ & \\
\hline $\mathbf{A B} 2 / 1$ & ${\text { isol-/val- }{ }^{-} \text {met }^{-}}^{-}$ & \\
\hline $\mathrm{AB} 2 / 2$ & isol- $^{-} / \mathrm{val}^{-} \mathrm{met}^{-}$ & \\
\hline $\mathrm{AB} 2 / 5$ & isol- $/ v a l^{-} a d^{-}$ & \\
\hline$A B 2 / 3$ & isol- $^{-}$val $^{-}$met $^{-}$ & AB 2 by u.v. irradation \\
\hline$A B 2 / 4$ & isol- $^{-}$val $^{-}$met $^{-}$ & \\
\hline $\mathrm{AB} 2 / 6$ & isol- $^{-}$val- $^{-}$met $^{-}$ & \\
\hline $\mathrm{AB} 2 / 7$ & isol- $^{-}$val- met $^{-}$ & \\
\hline $\mathrm{AB} 2 / 21$ & met $^{-}$ & $\mathrm{AB} 2 / 2$ \\
\hline $\mathrm{AB} 2 / 51$ & $a d^{-}$ & $A B 2 / 5$ \\
\hline AB 2/52 & $a d^{-}$ & AB $2 / 5$ spontaneous back mutation \\
\hline AB 2/10 & Prototroph & $\mathrm{AB} 2 / \mathbf{2}$ \\
\hline $\mathrm{AB} 2 / 22$ & Prototroph & $\mathbf{A B} 2$ \\
\hline
\end{tabular}

* The following abbreviations have been used: isol = isoleucine; val = valine; met = methionine; thr = threonine; cys = cysteine; arg = arginine; ur = uracil; his = histidine; ad = adenine $;$ phe $=$ phenylalanine; leu = leucine; tyr = tyrosine.

Difco antibiotic medium 3 was used for the microbiological determination of actinomycin production.

Isolation of mutants. Biochemical mutrtions were induced by ultraviolet (u.v.) 
irradiation. A spore suspension $\left(0.5 \mathrm{ml}\right.$. containing $5 \times 10^{7}$ spores in a Petri dish diam. $40 \mathrm{~mm}$.) was irradiated with a low-pressure mercury lamp to a survival of $10^{-2}$. Irradiated spores were plated on Bennett agar medium and incubated at $28^{\circ}$. After 4 days the colonies were replicated on minimal medium. Colonies which did not grow in minimal medium were isolated and their growth requirements characterized.

Production of actinomycin. Medium V6 $(5 \mathrm{ml}$.) was added to an agar slope culture and the spore suspension used to inoculate $100 \mathrm{ml}$. of the same medium in a $500 \mathrm{ml}$. Erlenmeyer flask. The cultures were incubated at $28^{\circ}$ on a reciprocating shaker for $24 \mathrm{hr}$. The mycelium was recovered by centrifugation, washed twice with the minimal fermentation medium and finally resuspended in $100 \mathrm{ml}$. of similar medium; $5 \mathrm{ml}$. of such a suspension was used as inoculum for each $100 \mathrm{ml}$. of fermentation media appropriately supplemented with the required nutrients. The fermentation flasks were incubated for $\mathbf{7 2} \mathrm{hr}$ under the conditions given above for the growth of the inoculum. All experiments were done in triplicate.

Bioassay of actinomycin. Liquid cultures were centrifuged and the supernatant solution was used for antibiotic assay with Bacillus subtilis ATCC 6633 as a test organism. The antibiotic titre was determined by the filter paper disk method, with crystalline actinomycin $\mathbf{D}$ as standard.

Growth curves. Cultures in appropriately supplemented minimal medium of two auxotroph strains were prepared as described above and incubated for $48 \mathrm{hr}$ on a reciprocating shaker. Samples $(10 \mathrm{ml}$.) of the cultures were removed at various time intervals and were centrifuged in graduated tubes for $15 \mathrm{~min}$. at $2500 \mathrm{rev} . / \mathrm{min}$. to determine the content of the mycelium, as \% of the total volume of the liquid culture. Each experiment was done in triplicate.

Organism. All the isolates used were derived from Streptomyces antibioticus no. 1692 (culture collection of the Institute of Botany, University of Pavia). A list of isolated strains is given in Table 1.

\section{RESULTS}

The actinomycins are a family of chromopeptide antibiotics which differ only in the peptide portion of the molecule (Brockmann, 1960). Streptomyces antibioticus strain 1692 produces in a minimal medium actinomycins $\mathrm{C}_{1}, \mathrm{C}_{2}$ and $\mathrm{C}_{3}$. The peptide portion of these actinomycins contains L-threonine, L-proline, sarcosine, L- $N$-methylvaline, D-valine and/or D-alloisoleucine (Fig. 1). Recent studies have shown that: L-proline is the precursor of the L-proline found in the actinomycins (Katz, Prockop \& Undenfriend, 1962); L-valine is the precursor of both the D-valine and $\mathrm{L}-\mathrm{N}$-methylvaline residues of the actinomycin molecule (Katz \& Weissbach, 1963); L-isoleucine is the precursor of the D-alloisoleucine (Albertini, Cassani \& Ciferri, 1964); L-threonine is the precursor of the L-threonine and, to a lesser extent, of the D-alloisoleucine (Albertini et al. 1964); glycine or sarcosine are the precursors of sarcosine (Ciferri, Albertini \& Cassani, 1964) in the molecule. Therefore, among the auxotrophs listed in Table 1, only those which require isoleucine and valine (e.g. $\mathrm{AB} 2, \mathrm{AB} 8, \mathrm{AB} 107)$ and threonine $(\mathrm{AB} 111)$ carry a deficiency for the synthesis of amino acids present in the proteins and in the antibiotic. On the other hand, the remaining strains are mutated in genes which control the synthesis of amino acids present only in the proteins. 
All isolates listed in Table 1 were tested for actinomycin production in complete medium and in minimal medium plus supplement, i.e. amino acid(s) required by the strain, at $10 \mu \mathrm{g}$. and $100 \mu \mathrm{g} . / \mathrm{ml}$.

The results are collected in Tables 2-4.

In complete medium, the average production of actinomycin by auxotrophs which required amino acids not present in the polypeptide was of the order of

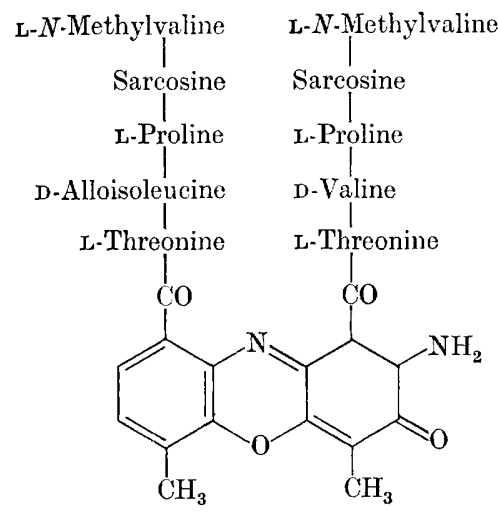

Fig. 1. Actinomycin $C_{2}$. In actinomycin $C_{1}$ the $D$-alloisoleucine is replaced by D-valine; in actinomycin $C_{3}$ the $D$-valine is replaced by $D$-alloisoleucine.

Table 2. Antibiotic production by Streptomyces antibioticus auxotrophs requiring as nutrients nitrogen bases or amino acids not present in the peptide chain of actinomycin

Strain

Code
AB 1
AB 3
AB 9
AB 115
AB 114
AB 4
AB 101
AB 102
AB 103
AB 113
AB 6
AB 106
AB 7
AB 10
AB 110
AB 109

Antibiotic production ( $\mu \mathrm{g} . / \mathrm{ml}$.)

\begin{tabular}{|c|c|c|c|}
\hline Requirement & $\begin{array}{c}\text { Complete } \\
\text { medium } \\
\text { V6 }\end{array}$ & $\begin{array}{l}\text { Minimal } \\
\text { medium } \\
+10 \mu \mathrm{g} . / \mathrm{ml} \text {. } \\
\text { of required } \\
\text { growth factor }\end{array}$ & $\begin{array}{c}\text { Minimal } \\
\text { medium } \\
+100 \mu \mathrm{g} . / \mathrm{ml} . \\
\text { of required } \\
\text { growth factor }\end{array}$ \\
\hline cys* & 135 & 35 & 38 \\
\hline $\arg +u r$ & 180 & 55 & 58 \\
\hline $\arg +\mathrm{ur}$ & 119 & 37 & 39 \\
\hline $\arg +u r$ & 120 & 35 & 33 \\
\hline arg & 110 & 31 & $\mathbf{3 3}$ \\
\hline his & 208 & 26 & 31 \\
\hline his & 122 & 28 & 29 \\
\hline his & 108 & 36 & 38 \\
\hline his & 98 & 27 & 28 \\
\hline ad & 118 & 35 & 30 \\
\hline phe & $\mathbf{5 2}$ & $6 \cdot 5$ & 8 \\
\hline leu & 88 & 18 & 20 \\
\hline leu & 74 & 16 & 17 \\
\hline leu & 92 & 19 & 22 \\
\hline met & 31 & $6 \cdot 5$ & 7 \\
\hline tyr & 80 & 15 & 18 \\
\hline Average & $108 \cdot 4$ & $26 \cdot 6$ & 28 \\
\hline $\begin{array}{l}\text { Wild type } \\
\text { Average }\end{array}$ & 106 & 25 & - \\
\hline
\end{tabular}

* Abbreviations see Table 1. 
$108 \mu \mathrm{g} . / \mathrm{ml}$., not significantly different from $106 \mu \mathrm{g} . / \mathrm{ml}$., the average production of the parental prototroph strain. In complete medium, the mutants which required amino acids which are potential precursors of actinomycin showed a significant

Table 3. Antibiotic production by Streptomyces antibioticus auxotrophs requiring amino acids which are present in protein and in the peptide chain of actinomycin

Strain

Code

AB 2
$\mathrm{AB} 8$
$\mathrm{AB} 107$
$\mathrm{AB} 111$
$\mathrm{AB} 2 / 1$
$\mathrm{AB} 2 / 2$
$\mathrm{AB} 2 / 5$
$\mathrm{AB} 2 / 3$
$\mathrm{AB} 2 / 4$
$\mathrm{AB} 2 / 6$
$\mathrm{AB} 2 / 7$

Antibiotic production ( $\mu \mathrm{g} . / \mathrm{ml}$.)

\begin{tabular}{|c|c|c|}
\hline $\begin{array}{l}\text { Complete } \\
\text { medium } \\
\text { V } 6\end{array}$ & $\begin{array}{c}\text { Minimal } \\
\text { medium } \\
+10 \mu \mathrm{g} \cdot / \mathrm{ml} \text {. } \\
\text { of required } \\
\text { amino acid }\end{array}$ & $\begin{array}{c}\text { Minimal } \\
\text { medium } \\
+100 \mu \mathrm{g} . / \mathrm{ml} . \\
\text { of required } \\
\text { amino acid }\end{array}$ \\
\hline 83 & 0.9 & $2 \cdot 7$ \\
\hline 70 & 0.8 & $2 \cdot 1$ \\
\hline 79 & $1 \cdot 0$ & $3 \cdot 8$ \\
\hline 68 & 0.7 & $3 \cdot 2$ \\
\hline 88 & $1 \cdot 0$ & $3 \cdot 3$ \\
\hline $12 \cdot 6$ & $1 \cdot 0$ & $1 \cdot 4$ \\
\hline 78 & 0.9 & $1 \cdot 2$ \\
\hline 30 & 0.8 & $1 \cdot 8$ \\
\hline 20 & 0.9 & $2 \cdot 1$ \\
\hline 45 & $1 \cdot 1$ & $2 \cdot 1$ \\
\hline 40 & $0 \cdot 8$ & $1 \cdot 2$ \\
\hline age $\mathbf{5 5 \cdot 7}$ & $0 \cdot 9$ & $2 \cdot 2$ \\
\hline 106 & 25 & - \\
\hline
\end{tabular}

* Abbreviations see Table 1.

Table 4. Antibiotic production by strains of Streptomyces antibioticus back-mutated to isoleucine and valine independence*

\begin{tabular}{|c|c|c|c|c|c|}
\hline \multirow[b]{2}{*}{ Code } & \multirow[b]{2}{*}{ Requirement } & \multirow[b]{2}{*}{ Derivation } & \multicolumn{3}{|c|}{ Antibiotic production ( $\mu \mathrm{g} . / \mathrm{ml})}$. \\
\hline & & & $\begin{array}{c}\text { Complete } \\
\text { medium } \\
\text { V } 6\end{array}$ & $\begin{array}{c}\text { Minimal } \\
\text { medium }+ \\
10 \mu \mathrm{g} . / \mathrm{ml} \text {. } \\
\text { of required } \\
\text { amino acid }\end{array}$ & $\begin{array}{c}\text { Minimal } \\
\text { medium }+ \\
100 \mu \mathrm{g} . / \mathrm{ml} \text {. } \\
\text { of required } \\
\text { amino acid }\end{array}$ \\
\hline $\mathrm{AB} 2 / 21$ & met & $\mathrm{AB} 2 / 2$ isol- $^{-} /$all $^{-}$met $^{-\dagger}$ & 198 & 66 & - \\
\hline$A B 2 / 51$ & ad & $\mathrm{AB} 2 / 5 \mathrm{isol}^{-} / \mathrm{val}^{-} \mathrm{ad}^{-}$ & 172 & 23 & - \\
\hline $\mathrm{AB} 2 / 52$ & ad & $\mathrm{AB} 2 / 5$ isol $^{-} / \mathrm{val}^{-} a d^{-}$ & 175 & $20 \cdot 5$ & - \\
\hline AB $2 / 22$ & - & $\mathrm{AB} 2 / 2$ isol- $^{-} /$val $^{-}$met $^{-}$ & $157 \cdot 5$ & - & $21 \cdot 5$ \\
\hline AB $2 / 10$ & - & $\mathrm{AB} 2$ isol- $^{-} /$val $^{-}$ & 100 & - & $12 \cdot 5$ \\
\hline
\end{tabular}

* The strain AB2/22 is back-mutated also to methionine independence.

$\dagger$ Abbreviations see Table 1 .

but not very marked decrease in production of actinomycin (average $56 \mu \mathrm{g} . / \mathrm{ml}$.). In minimal medium plus supplement of the amino acid required for growth, however, all the isolates showed a decrease in the synthesis of actinomycin. The yield of actinomycin was decreased on an average to $25 \%$ in the parental prototroph strain and in the auxotroph strains which required for growth amino acids not present in 
the antibiotic. The actinomycin yield was not significantly increased in this group of amino acid requiring mutants when the required amino acid supplement was increased from 10 to $100 \mu \mathrm{g} . / \mathrm{ml}$. (Table 2).

On the other hand, all the isolates which required for growth an amino acid which was a precursor of actinomycin (Table 3) showed in minimal medium (supplemented with the amino acid required for growth) a marked decrease in the production of actinomycin (about $2 \%$ of the yield in complete medium). The increase in the specifically required amino acid(s) from 10 to $100 \mu \mathrm{g} . / \mathrm{ml}$. resulted in a threefold increase of actinomycin yield; this was still very far from that of the other isolates listed in Table 2.

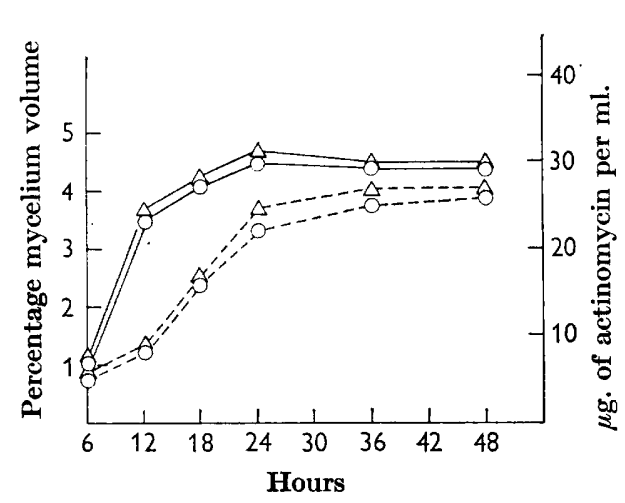

Fig. 2

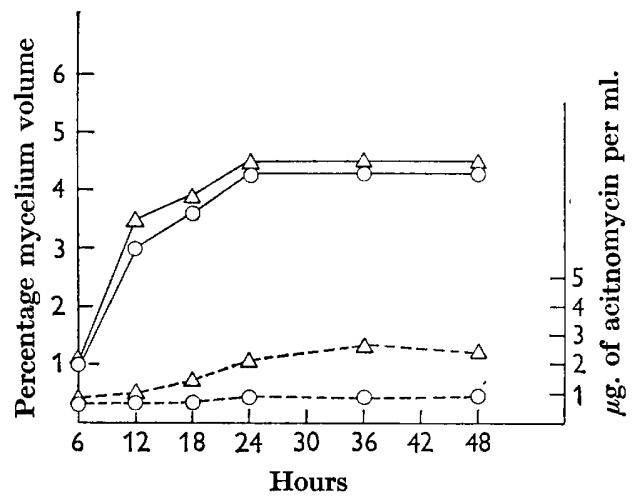

Fig. 3

Fig. 2. Growth curve and actinomycin production by the Streptomyces antibioticus mutant $A B 3$ arg $^{-}$ur. $^{-} \triangle \longrightarrow \triangle, O \longrightarrow O$, mycelium (\% by volume of the total cultural liquid) in minimal medium supplemented with 100 and $10 \mu \mathrm{g} . / \mathrm{ml}$. of the required growth factors, respectively. $\Delta \cdots \Delta, \bigcirc-\cdots$. , antibiotic production in minimal medium supplemented with 100 and $10 \mu \mathrm{g}$. $/ \mathrm{ml}$. of the required growth factors, respectively.

Fig. 3. Growth curve and actinomycin production by Streptomyces antibioticus mutant AB 2/2 isol $-/ \mathrm{val}^{-}$met $^{-}$. $\triangle \longrightarrow \triangle, O-O$, mycelium (\% by volume of the total cultural liquid) in minimal medium supplied with 100 and $10 \mu \mathrm{g} . / \mathrm{ml}$. of the required growth factors, respectively. $\triangle \cdots \triangle, \cdots_{-\cdots}-\cdots$, antibiotic production in minimal medium supplied with the required growth factors 100 and $10 \mu \mathrm{g} . / \mathrm{ml}$., respectively.

The fact that this behaviour was determined by the specific amino acid growth requirement is shown by the data of Table 4. Isolates carrying mutations for two kinds of amino acids, i.e. one required for actinomycin and protein synthesis and the other required for protein synthesis only, produced in minimal medium extremely low yields of antibiotic (Table 3). When these strains reverted to ability to synthesize the amino acid present in the antibiotic, the production of actinomycin became equal to that of the strains of the first group (Table 4).

A simple explanation for the above results could be that a very limited utilization of isoleucine, valine and threonine by all mutants requiring isoleucine, valine and threonine might result in scanty growth of the micro-organisms and therefore in a low production of antibiotic. This possibility was ruled out by the experiments reported in Figs. 2 and 3 which show that, despite very different yields of actinomycin in minimal media appropriately supplemented, two strains of different genotype showed equal growth rates which should indicate equal protein synthesis. 
The decrease in yield of actinomycin by the auxotrophs which required for growth a specific amino acid also present in the polypeptide chain should therefore be ascribed to a different phenomenon.

In the case of Bacillus anthracis, Gladstone (1939) observed that omission from the growth media of isoleucine, valine or leucine inhibited the growth of the microorganism. Such inhibition could be overcome by adding a mixture of all three amino acids. A similar 'toxic' effect brought about by threonine was removed by adding valine. It could be postulated, then, that such amino acids could exert a specific inhibition of the synthesis of actinomycin by Streptomyces antibioticus. However, the results obtained in the case of the prototroph $S$. antibioticus (Katz, 1960) showed that even very high levels of valine or isoleucine stimulate, rather than inhibit, growth and antibiotic production. Experiments performed on our mutant strains that carry a deficiency for valine and isoleucine revealed that the addition of a tenfold excess of leucine did not stimulate production of actinomycin. Nor did the addition of an excess of valine to fermentation media of the threonine-requiring strains have a beneficial effect.

\section{DISCUSSION}

MacDonald et al. (1963) suggested that 'the diminution of penicillin yield in Penicillium chrysogenum was most likely due to pleiotropic effects of the auxotrophic locus'. If this is an effect that occurs at random among mutants to auxotrophy, it is unlikely to explain our data because only mutations affecting the synthetic pathways of amino acids present in the polypeptide chain of actinomycin decrease the yield of actinomycin.

Our data are, at least in part, at variance with the data of Alikhanian et al. (1959), who observed in Streptomyces rimosus that the yield of antibiotic from some auxotrophs could be increased by the addition of an amino acid, for which the auxotroph was dependent, in amounts higher than those required only for growth. In our case, the production of actinomycin by the mutants of the first group (Table 2) seems to be unaffected by the concentration of the amino acid supplied to the culture.

The results obtained in minimal media may be explained as follows. The cell may recognize and utilize to different extents the amino acids absorbed from the environment and those synthesized by the cell itself, as reported, for instance, by Sercarz \& Gorini (1964) for the control of repressor formation by endogenous vs. exogenous arginine. Such different pools, or compartments, may be utilized rather efficiently and to approximately the same extent for protein synthesis. On the other hand, for the synthesis of the antibiotic polypeptide chain, the utilization of the external pool may be very inefficient since the production of actinomycin is decreased to $1 / 50$ of the normal at amino acid concentrations which support normal protein synthesis. Even a tenfold increase in the amino acid supplied stimulates only a threefold increase in the production of the antibiotic. Assuming that such a hypothesis is correct, one would then have to explain why in complete medium the production of antibiotic by the auxotrophs of Table 3 approaches a value near to that of the other mutants and of the prototroph. But it cannot be excluded a priori that the capacity of the cell to recognize two amino acid pools does not affect the utilization of small peptides or other possible precursors of the antibiotic present in the complete medium. 
The authors wish to thank Drs G. E. Magni and L. L. Cavalli-Sforza for critical suggestions and helpful advice and acknowledge the technical assistance of Miss P. Alti.

\section{REFERENCES}

Albertini, A., Cassani, G. \& Ciferri, O. (1964). Incorporation of L-isoleucine and L-threonine into the actinomycins synthesized by Streptomyces antibioticus. Biochim. biophys. Acta, 80, 655 .

Alikhanian, S.I., Mindlin, S. Z., Goldat, S. U. \& Vladimizov, A. V. (1959). Genetics of organisms producing tetracyclines. Ann. N.Y. Acad. Sci. 81, 914.

Bonner, D. (1947). Studies on the biosynthesis of penicillin. Arch. Biochem. 13, 1.

Brockmann, H. (1960). Structural differences of the actinomycins and their derivatives. Ann. N.Y. Acad. Sci. 89, 323.

Ciferri, O., Albertini, A. \& Cassani, G. (1964). Incorporation of sarcosine into the actinomycins synthesized by Streptomyces antibioticus. Biochem. J. 90, 82.

GLADSTone, G. P. (1939). Inter-relationship between amino acids in the nutrition of B. anthracis. Brit. J. exp. Path. $20,189$.

Goss, W. A. \& Katz, E. (1960). Production, isolation and properties of actinomycins II and III. Antibiotics \& Chemother. 10, 221.

Katz, E. (1960). Influence of valine, isoleucine and related compounds on actinomycin synthesis. J. biol. Chem. 235, 1090.

Katz, E., Prockop, D. J. \& Undenfriend, S. (1962). Precursors of the hydroxyproline and ketoproline in actinomycin. J. biol. Chem. 237, 1585.

Katz, E. \& Weissbach, H. (1963). Incorporation of $\mathrm{C}^{14}$-labelled amino acids into actinomycin and protein by Streptomyces antibioticus. J. biol. Chem. 238, 666 .

MacDonald, K. D., Hutchinson, J. M. \& Gillett, W. A. (1963). Isolation of auxotrophs of Penicillium chrysogenum and their penicillin yields. J. gen. Microbiol. 33, 365.

Mach, B., Reich, E. \& Tatum, E. L. (1963). Separation of the biosynthesis of the antibiotic polypeptide tyrocidine from protein biosynthesis. Proc. natn. Acad. Sci., U.S.A $50,175$.

Magni, G. E. \& von Borstex, R. C. (1962). Different rates of spontaneous mutation during mitosis and meiosis in yeast. Genetics, $47,1097$.

Sercarz, E. E. \& Gorini, L. (1964). Different contribution of exogenous and endogenous arginine to repressor formation. J. mol. Biol. 8, 254.

Sermonti, G. (1957). Produzione di penicillina da diploidi eterozigoti di Penicillium chrysogenum. Atti III Riunione Ass. Genet. it. Suppl. Ricerca scientifica, 27, 93.

Sermonti, G. (1959). Genetics of penicillin production. Ann. N.Y. Acad. Sci. 81, 950.

Waksman, S. A. (1961). The Actinomycetes, Vol. 2, p. 332. Baltimore: The Williams and Wilkins Co. 